\title{
Bismuth-Corlette Hilar Cholangiocarcinoma Classification
}

National Cancer Institute

\section{Source}

National Cancer Institute. Bismuth-Corlette Hilar Cholangiocarcinoma Classification. NCI Thesaurus. Code C134736.

A classification system of hilar cholang iocarcinoma that describes the location and extent of biliary infiltration by tumor. (AJCC 8th ed.) 